\title{
Electronic Media Exposure and Use among Toddlers
}

\author{
Hyoung Yoon Chang', Eun-Jin Park², Hee-Jeong Yoo ${ }^{3}$, Jee won Lee ${ }^{4}$, and Yunmi Shin ${ }^{凶}$ \\ ${ }^{1}$ Department of Psychiatry, Ajou University School of Medicine, Suwon, Republic of Korea \\ 2Department of Psychiatry, Inje University Ilsan Paik Hospital, Goyang, Republic of Korea \\ ${ }^{3}$ Department of Psychiatry, Seoul National University Bundang Hospital, Seoul National University College of Medicine, Seongnam, \\ Republic of Korea \\ ${ }^{4}$ Department of Psychiatry, Soonchunhyang University Bucheon Hospital, Bucheon, Republic of Korea
}

\begin{abstract}
Objective These days, young children are exposed to a wide range of smart devices and their usage of smart devices is rapidly increasing worldwide. However, the use of smart devices by young children has not been studied in detail yet because smart device is relatively recent. The purpose of this study was to investigate the exposure status of smart devices among 2-5 years old children in Korea.

Methods Four hundred parents of 2- to 5-year-old children were invited to enroll. Data on demographic information and the frequency of media use, time of media use, age at first use of media was self-reported.

Results Among 390 toddlers, $39.3 \%$ watched TV almost every day, while $12.0 \%$ of children used smartphone on a daily basis. During weekdays, $48 \%$ of the children watched TV for over an hour. On weekends, $63.1 \%$ of the children watched TV for over an hour. On weekends, $23.4 \%$ of children use their smartphones for over an hour. Children using smartphones before 24 months of age were $31.3 \%$.

Conclusion Research has shown that TV and smartphones are the most popular digital devices used by toddlers. Most toddlers began using smart devices at 12-24 months. This study provides comprehensive information on children's contemporary use of media.
\end{abstract}

Psychiatry Investig 2018;15(6):568-573

Key Words Toddler, Electronic media, Smart device, Exposure.

\section{INTRODUCTION}

These days, young children are exposed to a wide range of smart devices (e.g., smartphones and tablet computers) and their usage of smart devices is rapidly increasing worldwide. ${ }^{1-3}$ Recent results showing that $70-80 \%$ of under-fives in the UK use smart devices. ${ }^{4}$ According to Common Sense Media results, $72 \%$ of children aged $0-8$ used digital tools in 2013, compared with $38 \%$ in 2011 . The use of children under two years of age increased significantly from 10\% in 2011 to $38 \%$ in $2013 .{ }^{5}$ In Korea, the rate of use of smart devices is increasing rapidly and the proportion of children and adolescents using such devices is increasing. According to the Actual Situation of Infant \& Toddler Smartphone Exposure and

Received: April 1, 2017 Revised: June 18, 2017

Accepted: November 30, 2017

$\triangle$ Correspondence: Yunmi Shin, MD

Department of Psychiatry, Ajou University School of Medicine, 206 Worldcupro, Yeongtong-gu, Suwon 16499, Republic of Korea

Tel: +82-31-219-5180, Fax: +82-31-219-5179, E-mail: ymshin@ajou.ac.kr

(c) This is an Open Access article distributed under the terms of the Creative Commons Attribution Non-Commercial License (http://creativecommons.org/licenses/by$\mathrm{nc} / 4.0$ ) which permits unrestricted non-commercial use, distribution, and reproduction in any medium, provided the original work is properly cited.
Protection Measures' of the Child-Raising Policy Institute, infants and children's smartphone usage rate reached 53.1\% by 2013. The average age of first use of smartphones is 2.27 , which means that toddlers are already exposed to smartphones before he or she reaches the age of three. ${ }^{6}$ The average amount of time spent on smartphones per day for infants and toddlers was 31.65 minutes. ${ }^{7}$ The increasing amount of time children are spending on smart devices has raisen concerns on the impact of these behaviors on their psychological development. However, most of the recent research on children's use of technology focus mainly on school children and adolescents. ${ }^{8}$ According to Holloway et al., the use of smart devices by young children has not been studied comprehensively, because the introduction of smart devices is relatively recent and their usage are difficult to evaluate. ${ }^{9,10}$ Recognizing the rapidly changing use patterns of digital media use is important in determining how digital media is affecting children's lives. It is the most rudiment stage in understanding the impact of smart devices. The purpose of this study was to investigate the exposure status of smart devices (exposure time, content, initiation of first exposure) among 2-5 years old children. 


\section{METHODS}

\section{Study setting and study sample}

This research is a part of the Internet-Cohort for Understanding of internet addiction Risk factors/Rescue in Early livelihood (I-CURE) study. The I-CURE study is the first long term observational prospective cohort study that investigated the causes of internet-related diseases and disorders in children and adolescent.

After a detailed presentation on the design and purpose of the survey, 400 parents of 2- to 5-year-old children were invited to enroll their children in the study. All families involved in the survey gave their written informed consent and participated in the study voluntarily. All participants who completed the survey received individual evaluation results. Data were collected between December 1, 2015, through June 30, 2016 from the Suwon, Koyang, Sungnam city in Gyeonggi-do, Korea. Subsequently, the families of 390 children (97.5\% of those consenting) provided sufficient data to be included in the I-CURE study. The study was approved by the Institutional Review Board at the University of Ajou, School of Medicine (AJIRB-SBR-SUR-14-378).

\section{Demographic factors}

Parents reported their child's gender and their birthdate, main caregiver, family structure, maternal and paternal education level and employment status, and family income.

\section{Media measures}

\section{Household media ownership}

Respondents were asked if they had the following six types of media: smartphone, television, computers (e.g., desktops and laptops), tablet PC (e.g., iPad: Apple Inc., Cupertino, CA, USA; Galaxy Tab: Samsung Corp., Seoul, Korea), video consoles (e.g., Xbox: Microsoft, Redmond, UT, USA; PlayStation: Sony Corp., Tokyo, Japan), and portable device (e.g., Nintendo DS: Sony Computer Entertainment Inc., Tokyo, Japan).

\section{Media use}

Respondents were asked to report children's frequency of use of media. Response options were "never," "less than once a week," "1-2 days a week," "3-4 days a week," "5-6 days a week", and "almost every day." The data on average time their children spent on the media during the past month were also collected. The answers were divided into weekday and weekend. The response categories were none, 1 hour, 1-3 hour, 3-5 hours, 5 hours and up. Additionally, to evaluate children's age at first use, we asked parents, "How old was your child when she/he first did various activities on a media?" Response op- tions were "0-11 month," “12-23 month," “24-35 month," “36-47 month," “48-59 month.”

\section{Data analysis}

All statistical analyses were conducted using SAS version 9.3 (SAS Institute Inc., Cary, NC, USA). Missing data, representing unanswered questions, were not used in the data analysis. Frequency responses and percentages were obtained for each question and set of questions.

\section{RESULTS}

\section{Demographics}

The children had a mean age of $3.85 \pm 0.7(\mathrm{M} \pm \mathrm{SD})$ ages. Slightly more than half of the included sample (52.3\%) was boys. In most of the cases, the main caregiver was the mother (93.8\%). Majority of parents have received over 12 years of education (Mothers 87.4\%; fathers 88.2\%). Descriptive data are shown in Table 1.

\section{Frequency of media use}

Table 2 presents descriptive statistics regarding household media ownership and frequency of media use. Almost all households had televisions (94.6\%), personal computer (90\%), tablet PC (48.21\%) and smartphones (95.9\%). On the other hand, only a minority of household had video consoles (14.6\%), portable game devices (10.0\%). Smartphone has penetrated 95 percent of all households. $39.3 \%$ of the children watched TV almost every day. $12.0 \%$ of children used smartphone on a daily basis. $26.5 \%$ of the children were using smartphones more than 3 days a week, and more than $70 \%$ of the children watched TV more than 3 days a week.

\section{Time of media use}

Table 3 presents descriptive statistics regarding time using the devices.

The time spent on media is increased on weekends compared to weekdays. During the week, $48 \%$ of the children watch TV for over an hour. On weekends, $63.1 \%$ of the children watched TV for over an hour. During the week, $9.7 \%$ of children use the smartphone for more than an hour. On weekends, $23.4 \%$ of children use their smartphones for over an hour.

\section{Age at first use of media}

In the case of television, about $65 \%$ of children were exposed before 24 months. Before the age of 12 month, $12.2 \%$ of children were using smartphones for the first time. $31.3 \%$ of the children were using smartphones before 24 months of age (Table 4$)$. 
Table 1. Demographics of participants

\begin{tabular}{|c|c|}
\hline & Total $(\mathrm{N}=390)$ \\
\hline \multicolumn{2}{|l|}{ Age } \\
\hline 2 & $15(3.9)$ \\
\hline 3 & $120(30.8)$ \\
\hline 4 & $164(42.1)$ \\
\hline 5 & $91(23.4)$ \\
\hline \multicolumn{2}{|l|}{ Gender } \\
\hline Boys & $204(52.3)$ \\
\hline Girls & $186(47.7)$ \\
\hline \multicolumn{2}{|l|}{ Main caregiver } \\
\hline Mother & $363(93.8)$ \\
\hline Father & $1(0.3)$ \\
\hline Grandparents & $19(4.9)$ \\
\hline Other relatives & $2(0.5)$ \\
\hline Else & $2(0.5)$ \\
\hline \multicolumn{2}{|l|}{ Family structure } \\
\hline Both parents with child & $345(88.5)$ \\
\hline One parent with child & $5(1.3)$ \\
\hline Grandparent(s) with child & $1(0.3)$ \\
\hline Grandparent(s) plus both parents with child & $36(9.2)$ \\
\hline Grandparent(s) plus one parent with child & $3(0.8)$ \\
\hline \multicolumn{2}{|l|}{ Father's education level } \\
\hline$\geq 12$ years & $343(88.2)$ \\
\hline $9-11$ years & $42(10.8)$ \\
\hline$<9$ years & $3(0.8)$ \\
\hline Else & $1(0.3)$ \\
\hline \multicolumn{2}{|l|}{ Mother's education level } \\
\hline$\geq 12$ years & $341(87.4)$ \\
\hline 9-11 years & $46(11.8)$ \\
\hline$<9$ years & $2(0.5)$ \\
\hline Else & $1(0.3)$ \\
\hline \multicolumn{2}{|l|}{ Father's employment status $(\mathrm{N}=386)$} \\
\hline Day laborer & $3(0.8)$ \\
\hline Employee & $65(16.9)$ \\
\hline Owner-operator & $54(14.0)$ \\
\hline Office worker & $151(39.1)$ \\
\hline Middle manager & $76(19.7)$ \\
\hline Professional/ senior manager & $21(5.4)$ \\
\hline Artist/ religion worker & $10(2.6)$ \\
\hline Housewife/ no employment & $6(1.6)$ \\
\hline \multicolumn{2}{|l|}{ Mother's employment status $(\mathrm{N}=389)$} \\
\hline Day laborer & $2(0.5)$ \\
\hline Employee & $14(3.6)$ \\
\hline Owner-operator & $21(5.4)$ \\
\hline
\end{tabular}

Table 1. Demographics of participants (continued)

\begin{tabular}{lc}
\hline & Total $(\mathrm{N}=390)$ \\
\hline Office worker & $58(14.9)$ \\
Middle manager & $7(1.8)$ \\
Professional/senior manager & $26(2.7)$ \\
Artist/ religion worker & $13(3.3)$ \\
Housewife/no employment & $248(63.8)$ \\
Income per month & \\
$<\# 1,000,000$ & $6(1.5)$ \\
$¥ 1,000,000-2,000,000$ & $20(5.1)$ \\
$¥ 2,000,000-4,000,000$ & $172(44.1)$ \\
$\# 4,000,000-6,000,000$ & $124(31.8)$ \\
$\geq ¥ 6,000,000$ & $68(17.4)$ \\
\hline
\end{tabular}

Data represent $\mathrm{N}(\%)$

\section{DISCUSSION}

There has been a lack of empirical research on the exposure of smart devices for infants and toddlers. This is the first study to investigate the full range of media use of young children in Korea. In Korea, which has seen remarkable technological advances over the last few decades, electronic media devices have become more accessible and personalized. This study examined the use patterns of smart devices among children aged 2-5 years of age in community. As a result of the study, the majority of children lived in home environments using different digital devices and media.

Research has shown that TV and smartphones are the most popular digital devices used by children. TV viewing is considered as a passive activity that negatively affects cognition, physical and social development. ${ }^{11}$ In this study, 39\% of the toddlers used TV almost every day. On weekend, many children watched TV for more than an hour. In case of smartphones, on weekends, $23.4 \%$ of toddlers used their smartphones for over an hour. $31.3 \%$ of the children were using smartphones before 24 months of age.

The results are similar to other studies conducted in Korea. ${ }^{12}$ According to Hong's research, the average daily TV watching time of 2-year-old toddlers was 1.21 hours, and $32.6 \%$ of toddlers watched TV for more than 2 hours. This result is also similar to those of other countries. A study conducted in the Czech reported that children watched TV for an average of 1.2 to 1.5 hours per day. All participants spent more time on the media during weekends than on weekdays. On weekdays, children averaged less than 1 hour on average, and spent more than 78 minutes on weekends. ${ }^{13}$ In the UK, screening time for 5-6 year-old children was also found to use media for much more time on weekends than on weekdays. ${ }^{14}$

Compared to the previous study, the viewing time of the tele- 
vision is decreasing and the use time of the smart device is increasing gradually, the initiating age of the smart devices use is getting younger. ${ }^{6}$ According to a study conducted in Korea (2013), the time to start using smartphones was 2.27 years. $56.9 \%$ of toddlers were watching TV every day and $14.8 \%$ of toddlers were using smart devices every day. ${ }^{6}$ Although both studies differ in methodology and overexposure questions, the use of TV in toddlers is gradually decreasing, and the use of smart devices including smart phones is gradually increasing.
This tendency appears in the US and Europe, but it is showing up at high speed in Korea, where $98 \%$ of the population owns smartphones. As new media is integrated into children's lives, the time spent watching TV has slowed down over the last 20 years. Using data from the National Health and Nutrition Examination Survey (NHANES) between 2001 and 2012, the average time spent watching TV among preschool children was significantly reduced. ${ }^{15}$ On the other hand, the use of mobile devices (smartphones and tablet computers)

Table 2. Usage frequency of devices in toddlers

\begin{tabular}{lccccccc}
\hline & Owns the & \multicolumn{5}{c}{ Usage frequency } \\
\cline { 3 - 7 } & device & Does not use at all & $<$ 1 day/week & 1-2 days a week & 3-4 days a week & 5-6 days a week & Everyday \\
\hline TV & $369(94.6)$ & $32(8.3)$ & $25(6.5)$ & $52(13.4)$ & $69(17.8)$ & $57(14.7)$ & $152(39.3)$ \\
Computer & $351(90.0)$ & $241(62.6)$ & $71(18.4)$ & $40(10.4)$ & $23(6.0)$ & $5(1.3)$ & $5(1.3)$ \\
Tablet PC & $188(48.21)$ & $264(67.7)$ & $33(8.5)$ & $35(9.0)$ & $22(5.6)$ & $17(4.4)$ & $19(4.9)$ \\
Smartphone & $374(95.9)$ & $61(15.9)$ & $79(20.6)$ & $103(26.9)$ & $66(17.2)$ & $28(7.3)$ & $46(12.0)$ \\
Video & $57(14.6)$ & $373(95.9)$ & $7(1.8)$ & $6(1.5)$ & $2(0.5)$ & $0(0.0)$ & $1(0.3)$ \\
Portable game device & $39(10.0)$ & $385(99.0)$ & $2(0.5)$ & $2(0.5)$ & $0(0.0)$ & $0(0.0)$ & $0(0.0)$ \\
\hline
\end{tabular}

Data represent $\mathrm{N}(\%)$

Table 3. Hours using the devices in toddlers

\begin{tabular}{|c|c|c|c|c|c|}
\hline & Does not use at all & Less than 1 hour & $1-3$ hours & 3-5 hours & More than 5 hours \\
\hline \multicolumn{6}{|l|}{ During the weekday } \\
\hline TV & $66(17.1)$ & $135(34.9)$ & $163(42.1)$ & $19(4.9)$ & $4(1.0)$ \\
\hline Computer & $298(77.2)$ & $73(18.9)$ & $15(8.9)$ & $0(0.0)$ & $0(0.0)$ \\
\hline Tablet PC & $293(75.7)$ & $69(17.8)$ & $24(6.2)$ & $0(0.0)$ & $1(0.3)$ \\
\hline Smartphone & $133(34.8)$ & $212(55.5)$ & $34(8.9)$ & $3(0.8)$ & $0(0.0)$ \\
\hline Video & $383(99.0)$ & $2(0.5)$ & $2(0.5)$ & $0(0.0)$ & $0(0.0)$ \\
\hline Portable game device & $387(99.5)$ & $2(0.5)$ & $0(0.0)$ & $0(0.0)$ & $0(0.0)$ \\
\hline \multicolumn{6}{|l|}{ During the weekend } \\
\hline TV & $45(11.8)$ & $96(25.1)$ & $158(41.4)$ & $65(17.0)$ & $18(4.7)$ \\
\hline Computer & $289(74.5)$ & $66(17.0)$ & $26(6.7)$ & $6(1.6)$ & $1(0.3)$ \\
\hline Tablet PC & $288(74.4)$ & $61(15.7)$ & $31(8.0)$ & $6(1.6)$ & $1(0.3)$ \\
\hline Smartphone & $92(24.2)$ & $200(52.5)$ & $81(21.3)$ & $6(1.6)$ & $2(0.5)$ \\
\hline Video & 373 (95.6) & $12(3.1)$ & $4(1.0)$ & $1(0.3)$ & $0(0.0)$ \\
\hline Portable game device & $385(99.2)$ & $3(0.8)$ & $0(0.0)$ & $0(0.0)$ & $0(0.0)$ \\
\hline
\end{tabular}

Data represent $\mathrm{N}(\%)$

Table 4. Starting age of devices in toddlers

\begin{tabular}{lcccccc}
\hline & Does not use yet & 0-11 months old & 12-23 months old & 24-35 months old & 36-47 months old & $48-59$ months old \\
\hline TV & $32(8.3)$ & $104(26.9)$ & $153(39.6)$ & $42(10.9)$ & $28(7.3)$ & $27(7.0)$ \\
Computer & $241(62.4)$ & $11(2.8)$ & $25(6.5)$ & $41(10.6)$ & $43(11.1)$ & $25(6.5)$ \\
Tablet PC & $264(68.4)$ & $4(1.0)$ & $23(6.0)$ & $42(10.9)$ & $34(8.8)$ & $19(4.9)$ \\
Smartphone & $61(16.2)$ & $46(12.2)$ & $118(31.3)$ & $74(19.6)$ & $39(10.3)$ & $39(1.03)$ \\
Video & $373(96.1)$ & $1(0.3)$ & $4(1.0)$ & $2(0.5)$ & $4(1.0)$ & $4(1.0)$ \\
Portable game device & $385(99.0)$ & $0(0.0)$ & $0(0.0)$ & $1(0.3)$ & $1(0.3)$ & $2(0.5)$ \\
\hline
\end{tabular}

Data represent $\mathrm{N}(\%)$ 
by young children has increased dramatically since the Kaiser Family Foundation began research into the use of technology for parents of 0 - to 8 -year-olds. ${ }^{3}$ In 2011, 52\% of children aged $0-8$ were able to access mobile devices, but by 2013 they increased to $75 \%{ }^{5}$

Smart devices are becoming increasingly popular in the homes of young children. ${ }^{16}$ Touch-based multi-modal interface smart device provides an easy-to-use platform for young children, especially when compared to a mouse that require fine motor and keyboard techniques. The impact of smart devices on the physical, cognitive, and social development of young children is limited for a number of reasons. ${ }^{17}$

Many studies have shown that excessive screen time for young children is associated with language delay, attention problems, obesity, aggressive behavior, sleep problems. ${ }^{4,10,18,19}$ In addition, screen time habits formed at young childhood can later predict negative psychological and health outcomes in life. ${ }^{20-22}$ Thus, building appropriate screen time habits in young children can have a significant impact on their health and well-being throughout their lifetime. Factors affecting screen time for school-aged children and adolescents may not be relevant to young children's group because early developmental stages are distinct periods. Early use of media, increased cumulative time of media usage, and media content are all important independent predictors of poor executive functioning. ${ }^{23}$ Because directional reactions to new stimuli are very strong for young children, they pay attention to the attractive and fast-changing features of smart devices such as animation, sound, and highlighting. ${ }^{13}$ However, these features can decrease the comprehension of young children. ${ }^{24}$ There is little research on media use for preschool children. However, when young children play video games or use the computer, they use these media for just under an hour, which is not a trivial amount of time in a young child's day. The results of this survey clearly show that young children are growing in environments exposed to media. According to one study in the United States, ${ }^{25} 90 \%$ of children have already started watching television by age 2 , and a Canadian survey shows that $25 \%$ of 2-5 year olds watch TV for more than 2 hours each day. In this study, too many children are exposed to TV and smart device before 24 months.

The findings of this study cannot be generalized to overall population because of the relatively small sample size and largely homogenous SES backgrounds. Also, current survey data is based on a questionnaire written by parents, which may be vulnerable to socially undesirable biases. Future research will provide more reliable data by directly observing the use of electronic and measuring screen time in the homes.

In order to provide a stronger rationale for the screen time guidelines, we must consider the broader factors that affect use of smart devices, such as parent factors, environment, and child's factors.

In recent years, over-exposure to smart devices has become an important area in the public mental health field. The majority of children spend more time watching screen media than ever before. Despite concerns about overuse of smart devices by children, research on Asian countries is very limited. Most smart device overexposure studies are being conducted in the US and Europe. The findings do not examine the impact of smart devices on children and families. They simply describe the characteristics and usage patterns of smart device exposure. Although TV is still the most common type of screen device that exposes children, this research shows that smartphones are the second most commonly used screen media in addition to TVs. Research shows that over the weekend, TV viewing and smartphone usage are particularly high, so weekend can be an important goal in mediation to reduce screen time. To encourage healthy screen habits from childhood, doctors and mental health professionals should educate parents about the impact that media exposure can have on their children and be aware of their importance.

\section{Acknowledgments}

This research was supported by the grant from the Korean Mental Health Technology R\&D Project, Ministry of Health \& Welfare, Republic of Korea (HM14C2603).

\section{REFERENCES}

1. Jordan AB, Woodard E. Electronic childhood: the availability and use of household media by 2-to 3-year-olds. Zero Three 2001;22:4-9.

2. Huston AC, Wright JC, Marquis J, Green SB. How young children spend their time: television and other activities. Dev Psychol 1999;35:912925.

3. Media CS, Rideout V. Zero to Eight: Children's Media Use in America. San Francisco: Common Sense Media; 2011.

4. Owens J, Maxim R, McGuinn M, Nobile C, Msall M, Alario A. Television-viewing habits and sleep disturbance in school children. Pediatrics 1999;104:e27-e27.

5. Dennison BA, Erb TA, Jenkins PL. Television viewing and television in bedroom associated with overweight risk among low-income preschool children. Pediatrics 2002;109:1028-1035.

6. Lee JR. A Study on Smart-Media Exposure of Early Childhood. Seoul: Korea Institute of Child Care and Education; 2013.

7. Gorely T, Marshall SJ, Biddle SJ. Couch kids: correlates of television viewing among youth. Int J Behav Med 2004;11:152-163.

8. Rideout V. Parents, Media and Public Policy: A Kaiser Family Foundation Survey. Menlo Part, CA: Kaiser Family Foundation; 2004.

9. Holloway D, Green L, Livingstone S. Zero to Eight: Young Children and Their Internet Use. LSE, London: EU Kids Online; 2013.

10. Linebarger DL, Walker D. Infants' and toddlers' television viewing and language outcomes. Am Behav Sci 2005;48:624-645.

11. Sweetser P, Johnson D, Ozdowska A, Wyeth P. Active versus passive screen time for young children. Aust J Early Child 2012;37:94-98.

12. Byeon H, Hong S. Relationship between television viewing and language delay in toddlers: evidence from a Korea national cross-sectional survey. PLoS one 2015;10:e0120663.

13. Sigmundová D, Sigmund E, Badura P, Vokáčová J, Trhlíková L, Bucksch 
J. Weekday-weekend patterns of physical activity and screen time in parents and their pre-schoolers. BMC Public Health 2016;16:898.

14. Jago R, Thompson JL, Sebire SJ, Wood L, Pool L, Zahra J, et al. Crosssectional associations between the screen-time of parents and young children: differences by parent and child gender and day of the week. Int J Behav Nutr Phys Act 2014;11:54.

15. 2014 KCC. Mass Media Use Behaviour Survey. Seoul: Nanum Communications; 2015.

16. Livingstone S, Marsh J, Plowman L, Ottovordemgentschenfelde S, Fletcher-Watson B. Young Children (0-8) and Digital Technology. London: London School of Economics and Political Science; 2014.

17. Neumann MM. Young children and screen time: creating a mindful approach to digital technology. Aust Educ Comput 2015;30:1-15.

18. Tomopoulos S, Dreyer BP, Berkule S, Fierman AH, Brockmeyer, Mendelsohn AL. Infant media exposure and toddler development. Arch Pediatr Adolesc Med 2010;164:1105-1111.

19. Kostyrka-Allchorne K, Cooper NR, Simpson A. The relationship between television exposure and children's cognition and behaviour: a systematic review. Dev Rev 2017;44:19-58.
20. Thorp AA, Owen N, Neuhaus M, Dunstan DW. Sedentary behaviors and subsequent health outcomes in adults: a systematic review of longitudinal studies, 1996-2011. Am J Prev Med 2011;41:207-215.

21. Proper KI, Singh AS, van Mechelen W, Chinapaw MJ. Sedentary behaviors and health outcomes among adults: a systematic review of prospective studies. Am J Prev Med 2011;40:174-182.

22. Pagani LS, Fitzpatrick C, Barnett TA, Dubow E. Prospective associations between early childhood television exposure and academic, psychosocial, and physical well-being by middle childhood. Arch Pediatr Adolesc Med 2010;164:425-431.

23. Hinkley T, Salmon J, Okely AD, Trost SG. Correlates of sedentary behaviours in preschool children: a review. Int J Behav Nutr Phys Act 2010;7:66

24. Tandon PS, Zhou C, Lozano P, Christakis DA. Preschoolers' total daily screen time at home and by type of child care. J Pediatr 2011;158:297300 .

25. American Academy of Pediatrics. Committee on Public Education. Media education. Pediatrics 1999;104:341-343. 